\title{
SWAHILI TERMS
}

Askari

African policeman or soldier

Kiboko

hippopotamus; whip made of dried hippopotamus hide

Mtoto (pl: watoto) child (usu. toto when used by settlers)

Mshenzi (pl: washenzi) savage, uncivilized person (usu. shenzi when used by settlers)

Mzungu (pl: wazungu) white person

Panga machete

Serikali

government 